\title{
Article
}

\section{The Characteristics of Patients with Oral Lichen Planus and Malignant Transformation-A Retrospective Study of 271 Patients}

\author{
Vladimíra Radochová *(D), Romana Koberová Ivančaková (D), Ondřej Heneberk (D) and Radovan Slezák \\ Department of Dentistry, Faculty of Medicine and University Hospital in Hradec Králové, Charles University, \\ Sokolská 581, 50005 Hradec Králové, Czech Republic; koberovar@lfhk.cuni.cz (R.K.I.); \\ ondrej.heneberk@fnhk.cz (O.H.); slezak@lfhk.cuni.cz (R.S.) \\ * Correspondence: vladimira.radochova@lfhk.cuni.cz; Tel.: +42-06-0772-9029
}

Citation: Radochová, V.; Koberová Ivančaková, R.; Heneberk, O.; Slezák, R. The Characteristics of Patients with Oral Lichen Planus and Malignant Transformation-A Retrospective Study of 271 Patients. Int. J. Environ. Res. Public Health 2021, 18, 6525. https://doi.org/10.3390/ ijerph18126525

Academic Editor: Gianrico Spagnuolo

Received: 28 April 2021

Accepted: 15 June 2021

Published: 17 June 2021

Publisher's Note: MDPI stays neutral with regard to jurisdictional claims in published maps and institutional affiliations.

Copyright: (c) 2021 by the authors. Licensee MDPI, Basel, Switzerland. This article is an open access article distributed under the terms and conditions of the Creative Commons Attribution (CC BY) license (https:// creativecommons.org/licenses/by/ $4.0 /)$.

\begin{abstract}
Introduction: Oral lichen planus (OLP) is a chronic inflammatory disease with an unknown etiology rating among oral potentially malignant disorder. The aim of the study was to determine the epidemiological and clinical characteristics of the patients with OLP and rate of malignant transformation. Patients and methods: Data were obtained from the medical records of 271 patients referred to the Oral Medicine Unit at the University Hospital in Hradec Králove diagnosed with oral lichen planus in the period of 2003-2020. The records were retrospectively analyzed. The following clinical data were retrieved from the medical charts: gender, age, systemic diseases, alcohol and tobacco consumption, localization/clinical appearance of lesions, distribution of the lesions, presence of the symptoms, treatment provided and malignant transformation. Results: A total of 271 charts of patients with confirmed diagnosis of OLP were retrospectively analyzed, of whom, $66.4 \%(180 / 271)$ were women and $33.6 \%(91 / 271)$ were men. The mean age of the patients was $56.0(18.2-85.0)$ years. The median follow-up of all patients was 15.2 months. Overall, 2 patients $(2 / 271,0.74 \%)$ meeting the above-mentioned criteria for malignant transformation were identified during the follow-up period. Both patients suffered from erosive type OLP and developed squamous cell carcinoma of the tongue. Conclusions: This retrospective study is in concordance with other studies showing the similar profile and clinical features of the patients with OLP. Malignant transformation rate was $0.74 \%$.
\end{abstract}

Keywords: oral lichen planus; malignant transformation; clinical features

\section{Introduction}

Oral lichen planus (OLP) is the chronic or recurrent autoimmune disease of the oral mucosa [1]. Although the etiopathogenesis of OLP is unknown the immune system plays a very important role in disease development [2]. Both antigen-specific and non-specific mechanisms may be involved in the pathogenesis of oral lichen planus [3]. The prevalence of OLP is believed to be around 1\% worldwide. Higher prevalence was reported in Europe $(1.43 \%)$ and lower in India $(0.49 \%)$ [4]. The prevalence increases significantly and progressively with age, especially over the age of 40 [4]. OLP is characterized by the presence of white lace-like reticular lesions with or without erosive and atrophic lesions [3]. The clinical picture is characterized by changing type/forms of lesions over time. Andreasen was the first who classified OLP and postulated the existence of six different clinical forms [5]. Later, this classification was simplified by other authors who basically divided the clinical forms of OLP into reticular, papular, atrophic and erosive lesions or only for red and white forms [6]. Any intraoral area can be affected, the most commonly affecting the buccal mucosa and lateral tongue; these lesions are almost always present bilaterally. The gingiva and alveolar mucosa are also frequently affected and desquamative gingivitis can be present. The diagnosis of OLP should be based on the combination of clinical and histopathological criteria [7]. Histopathological criteria are: presence of well-defined band such as predominantly lymphocytic infiltrate that is confined to the superficial part of connective tissue, hyperorthokeratosis or hyperparakeratosis, acanthosis, thickening 
of the spinous layer, liquefaction of the basal layer accompanied by the degeneration of keratocytes and lymphocyte infiltration of the lamina propria [8,9]. It is also critically important to distinguish OLP and other disorders with similar clinical appearance such as oral lichenoid lesions [10]. OLP has been classified as an oral potentially malignant disorder since the first WHO workshop in 2005 [11]. The malignant transformation of OLP was reported to be around 2\% [12]. The aim of the study was to evaluate the characteristics of patients with OLP and evaluate malignant transformation cases in the cohort of patients treated and followed up at our institution.

\section{Materials and Methods}

The report was approved by the local ethical committee. All consecutive patients at the Oral Medicine Unit, the Department of Dentistry, Charles University in Prague, Faculty of Medicine and University Hospital in Hradec Králové, Czech Republic, diagnosed with OLP from 2003 to December 2020 were included in the study. All patients had histologically confirmed clinical diagnosis of OLP according to the diagnostic criteria of the World Health Organization (WHO) 1978 modified by van der Meij et al. in 2003 [8]. We excluded patients with oral lichenoid contact lesions caused by an identifiable cause such as a hypersensitivity reaction to dental restorative materials or patients with suspected drug-induced lesions (patients on chronic medication unchanged for one year or longer were eligible). We did not exclude patients with epithelial dysplasia. The following clinical data were obtained from the medical charts: gender, age, alcohol and tobacco consumption, clinical types of lesions and localization of the lesions, presence of the symptoms, extraoral manifestations of lichen planus, presence of systemic diseases, history of the medication, treatment provided (topical corticosteroid in mucosal adhesive paste or intralesional injection or systemic corticosteroid). Malignant transformation case was defined as the development of new histologically confirmed malignant tumor at the site simultaneously affected by OLP. We have also analyzed the patients according to three subgroups: the first group comprises of the reticular and plaque lesions ("white" lesions), the second group comprises of erythematous lesions and desquamative gingivitis ("red" lesions) and the third group included patients with erosive, ulcerative and bullous lesions ("erosive" lesions). The patient with more types of simultaneous lesions was classified according to the worst clinical presentation (erosive considered as the most serious). We compared the groups for the possible clinical differences. A descriptive statistical analysis was made using Microsoft Excel 2003 (Microsoft, Redmond, WA, USA) and MedCalc 9.5.2.0 (MedCalc Software, Ostend, Belgium). Data were described by absolute and relative frequencies of categorical variables and mean (minimum-maximum) of quantitative variables. For comparison of categorical variables in groups ML, chi-squared test was used, in the case of quantitative variables the Mann-Whitney $\mathrm{U}$ test was adopted. $p$-values less than 0.05 were considered statistically significant (all tests two-sided).

\section{Results}

A total of 271 patient's charts with confirmed diagnosis of OLP were retrospectively analyzed; $66.4 \%$ (180/271) were women and 33.6\% (91/271) were men, giving a female to male ratio of 1.98:1. All affected patients were white Caucasian. The mean age of the patients at the time of examination was $56.0(18.2-85.0)$ years, mean age was 56.1 (18.2-85.0) for women and 50.6 (18.9-74.1) for men and the difference was statistically significantly different $(p=0.0009)$. Detailed data regarding the characteristics of the patients can be found in Table 1. 
Table 1. Basic characteristic of all patients.

\begin{tabular}{|c|c|c|c|c|c|c|c|}
\hline Variable & All (N) & $\%$ & Males & $\%$ & Females & $\%$ & $p$-Value * \\
\hline Age (mean, range) & 56.0 & $(18.2-85.0)$ & 50.6 & $(18.9-74.1)$ & 56.1 & $(18.2-85.0)$ & 0.0009 \\
\hline Female gender & 180 & 66.4 & 0 & 0.0 & 180 & 100.0 & \\
\hline Male gender & 91 & 33.6 & 91 & 100.0 & 0 & 0.0 & \\
\hline \multicolumn{8}{|l|}{ Systemic disorders } \\
\hline Arterial hypertension & 128 & 47.2 & 34 & 37.4 & 94 & 52.2 & 0.0289 \\
\hline Diabetes mellitus & 38 & 14.0 & 12 & 13.2 & 26 & 14.4 & 0.9232 \\
\hline Cardiac disease & 29 & 10.7 & 6 & 6.6 & 23 & 12.8 & 0.1779 \\
\hline Psychiatric disease & 22 & 8.1 & 0 & 0.0 & 22 & 12.2 & 0.0012 \\
\hline Thyroid gland disease & 54 & 19.9 & 4 & 4.4 & 50 & 27.8 & $<0.0001$ \\
\hline Other & 115 & 42.4 & 28 & 30.8 & 87 & 48.3 & 0.0085 \\
\hline \multicolumn{8}{|l|}{ Confounding factors } \\
\hline Drugs & 190 & 70.1 & 50 & 54.9 & 140 & 77.8 & 0.0002 \\
\hline Allergies & 52 & 19.2 & 15 & 16.5 & 37 & 20.6 & 0.5218 \\
\hline Smoking & 52 & 19.2 & 19 & 20.9 & 31 & 17.2 & 0.5706 \\
\hline Amalgam restorations & 205 & 75.6 & 74 & 81.3 & 131 & 72.8 & 0.1624 \\
\hline Artificial crowns & 105 & 38.7 & 34 & 37.4 & 71 & 39.4 & 0.8413 \\
\hline Other restorations & 36 & 13.3 & 8 & 8.8 & 28 & 15.6 & 0.1738 \\
\hline \multicolumn{8}{|l|}{ Subjective symptoms } \\
\hline Burning on food ingestion & 182 & 67.2 & 51 & 56.0 & 131 & 72.8 & 0.0085 \\
\hline Constant pain & 71 & 26.2 & 17 & 18.7 & 54 & 30.0 & 0.0636 \\
\hline \multicolumn{8}{|l|}{ Extraoral lesions } \\
\hline Skin & 47 & 17.3 & 12 & 13.2 & 35 & 19.4 & 0.2648 \\
\hline Genital & 14 & 5.2 & 4 & 4.4 & 10 & 5.6 & 0.0907 \\
\hline \multicolumn{8}{|l|}{ Lesions distribution } \\
\hline Buccal & 248 & 91.5 & 84 & 92.3 & 164 & 91.1 & 0.9179 \\
\hline Alveolar ridge & 97 & 35.8 & 37 & 40.7 & 60 & 33.3 & 0.2919 \\
\hline Tongue & 152 & 56.1 & 50 & 54.9 & 102 & 56.7 & 0.8886 \\
\hline Palate & 20 & 7.4 & 4 & 4.4 & 16 & 8.9 & 0.2756 \\
\hline Lips & 60 & 22.1 & 22 & 24.2 & 38 & 21.1 & 0.6752 \\
\hline Mouth floor & 12 & 4.4 & 5 & 5.5 & 7 & 3.9 & 0.7686 \\
\hline \multicolumn{8}{|l|}{ OLP form } \\
\hline Reticular & 259 & 95.6 & 87 & 95.6 & 172 & 95.6 & 0.7686 \\
\hline Erosive & 136 & 50.2 & 35 & 38.5 & 101 & 56.1 & 0.0089 \\
\hline Erythematous & 120 & 44.3 & 33 & 36.3 & 87 & 48.3 & 0.0785 \\
\hline Plaque & 111 & 41.0 & 37 & 40.7 & 74 & 41.1 & 0.9527 \\
\hline Ulcerative & 37 & 13.7 & 9 & 9.9 & 28 & 15.6 & 0.2733 \\
\hline Bullous & 2 & 0.7 & 0 & 0.0 & 2 & 1.1 & 0.7965 \\
\hline Desquamative gingivitis & 54 & 19.9 & 12 & 13.2 & 42 & 23.3 & 0.0697 \\
\hline \multicolumn{8}{|l|}{ Treatment required } \\
\hline No treatment & 93 & 34.3 & 42 & 46.2 & 51 & 28.3 & 0.0054 \\
\hline $\begin{array}{l}\text { Any treatment } \\
\text { administered }\end{array}$ & 178 & 65.7 & 49 & 53.8 & 129 & 71.7 & 0.0054 \\
\hline Topical steroid & 170 & 62.7 & 45 & 49.5 & 125 & 69.4 & 0.0021 \\
\hline Intralesional steroid & 80 & 29.5 & 21 & 23.1 & 59 & 32.8 & 0.1304 \\
\hline Systemic steroid & 19 & 7.0 & 6 & 6.6 & 13 & 7.2 & 0.9518 \\
\hline Malignant transformation & 2 & 0.7 & 1 & 1.1 & 1 & 0.6 & 0.2477 \\
\hline
\end{tabular}

* Chi-squared test.

\subsection{Systemic Diseases, Medication, Smoking}

The most prevalent concomitant systemic disorders included arterial hypertension in $47.2 \%$ (128/271), thyroid gland disorders in $19.9 \%$ (54/271), diabetes mellitus in $14.0 \%$ (38/271), psychiatric diseases $8.1 \%(22 / 271)$ and other various diseases in $42.4 \%(115 / 271)$ patients. Positive allergy history was present in 19.2\% (52/271) patients. 70.1\% (190/271) patients were on regular medication. 19.2\% (52/271) of patients were smokers.

\subsection{Extraoral Manifestations}

Skin lesions were observed in $17.3 \%$ ( $47 / 271$ patients) of the patients ( 12 men, 35 women). Genital lesions with LP were found in 5.2\% (14/271) of patients (4 men, 10 women). 


\subsection{Clinical Types of Oral Lichen Planus and Distribution}

The most common type was the reticular form of the OLP which was observed in $259 / 271(95.6 \%)$ patients. $12 / 271(4.4 \%)$ patients did not show any reticula and were presented only by other clinical forms. The erosive form was the second most common type with the prevalence of 136/271 (50.2\%) patients. Prevalence of the erythematous lesions was $120 / 271(44.3 \%)$ and plaque form was in $111 / 271(41.0 \%)$ patients. Desquamative gingivitis was present in 54/271 (19.9\%) patients. In all cases of desquamation, there was a combination with another form of OLP. The buccal mucosa being the most common location of each clinical form $(248 / 271,91.5 \%)$, followed by the tongue $(93 / 171,54.4 \%)$, gingiva and alveolar mucosa $(44 / 171,25.7 \%)$, lips $(32 / 171,18.7 \%)$. Lesions of the palate $(20 / 271,7.4 \%)$ and floor of the mouth $(12 / 271,4.4 \%)$ were uncommon. The comparison of subgroups is presented in Table 2.

Table 2. Comparison of subgroups of patients.

\begin{tabular}{|c|c|c|c|c|c|c|c|}
\hline Variable & White & $\%$ & Red & $\%$ & Erosive & $\%$ & $p$-Value * \\
\hline & $\mathrm{N}=106$ & & $\mathrm{~N}=25$ & & $\mathrm{~N}=140$ & & \\
\hline Age (mean, range) & 50.9 & $(18.2-78.5)$ & 53.4 & $(24.5-74.1)$ & 57.0 & $(18.9-85.0)$ & 0.0036 \\
\hline Female gender & 59 & 55.7 & 17 & 68.0 & 104 & 74.3 & \\
\hline Male gender & 47 & 44.3 & 8 & 32.0 & 36 & 25.7 & \\
\hline \multicolumn{8}{|l|}{ Systemic disorders } \\
\hline Arterial hypertension & 47 & 44.3 & 10 & 40.0 & 71 & 50.7 & 0.458 \\
\hline Diabetes mellitus & 13 & 12.3 & 2 & 8.0 & 23 & 16.4 & 0.4282 \\
\hline Cardiac disease & 11 & 10.4 & 2 & 8.0 & 16 & 11.4 & 0.8693 \\
\hline Psychiatric disease & 7 & 6.6 & 2 & 8.0 & 13 & 9.3 & 0.7474 \\
\hline Thyroid gland disease & 17 & 16.0 & 5 & 20.0 & 32 & 22.9 & 0.4151 \\
\hline Other & 39 & 36.8 & 10 & 40.0 & 66 & 47.1 & 0.2576 \\
\hline \multicolumn{8}{|l|}{ Confounding factors } \\
\hline Drugs & 71 & 67.0 & 17 & 68.0 & 102 & 72.9 & 0.5908 \\
\hline Allergies & 21 & 19.8 & 4 & 16.0 & 27 & 19.3 & 0.2786 \\
\hline Smoking & 24 & 22.6 & 7 & 28.0 & 19 & 13.6 & 0.0834 \\
\hline Amalgam restorations & 84 & 79.2 & 19 & 76.0 & 102 & 72.9 & 0.5122 \\
\hline Artificial crowns & 37 & 34.9 & 12 & 48.0 & 56 & 40.0 & 0.4375 \\
\hline Other restorations & 10 & 9.4 & 3 & 12.0 & 23 & 16.4 & 0.2723 \\
\hline \multicolumn{8}{|l|}{$\begin{array}{l}\text { Subjective } \\
\text { symptoms }\end{array}$} \\
\hline $\begin{array}{c}\text { No symptoms/occasional } \\
\text { burning }\end{array}$ & 55 & 51.9 & 1 & 4.0 & 0 & 0.0 & $<0.0001$ \\
\hline Burning on food ingestion & 47 & 44.3 & 21 & 84.0 & 114 & 81.4 & $<0.0001$ \\
\hline Constant pain & 4 & 3.8 & 3 & 12.0 & 64 & 45.7 & $<0.0001$ \\
\hline \multicolumn{8}{|l|}{ Extraoral lesions } \\
\hline Skin & 15 & 14.2 & 4 & 16.0 & 28 & 20.0 & 0.4785 \\
\hline Genital & 3 & 2.8 & 3 & 12.0 & 8 & 5.7 & 0.1612 \\
\hline \multicolumn{8}{|l|}{ Lesions distribution } \\
\hline Buccal & 97 & 91.5 & 20 & 80.0 & 131 & 93.6 & 0.0809 \\
\hline Alveolar ridge & 23 & 21.7 & 12 & 48.0 & 62 & 44.3 & 0.0005 \\
\hline Tongue & 45 & 42.5 & 15 & 60.0 & 92 & 65.7 & 0.0012 \\
\hline Palate & 2 & 1.9 & 5 & 20.0 & 13 & 9.3 & 0.0036 \\
\hline Lips & 10 & 9.4 & 8 & 32.0 & 42 & 30.0 & 0.0003 \\
\hline Mouth floor & 1 & 0.9 & 1 & 4.0 & 10 & 7.1 & 0.0642 \\
\hline \multicolumn{8}{|l|}{ Treatment required } \\
\hline No treatment & 25 & 23.6 & 7 & 28.0 & 62 & 44.3 & 0.0025 \\
\hline $\begin{array}{l}\text { Any treatment } \\
\text { administered }\end{array}$ & 81 & 76.4 & 18 & 72.0 & 78 & 55.7 & 0.0025 \\
\hline Topical steroid & 75 & 70.8 & 17 & 68.0 & 78 & 55.7 & 0.0459 \\
\hline Intralesional steroid & 41 & 38.7 & 6 & 24.0 & 33 & 23.6 & 0.0299 \\
\hline Systemic steroid & 1 & 0.9 & 0 & 0.0 & 18 & 12.9 & 0.0005 \\
\hline Malignant transformation & 0 & 0.0 & 0 & 0.0 & 2 & 1.4 & 0.082 \\
\hline
\end{tabular}

* Chi-squared test. 


\subsection{Treatment}

Topical steroids alone were prescribed to 170/271 (62.7\%) and in combination with systemic steroids to $19 / 271(7.0 \%)$ of the patients. 93/271 (34.3\%) patients didn't use any drug (asymptomatic or the symptoms were very small). Dexamethasone gel was used for the local treatment which patients applied several times per day to the most symptomatic areas. In 80/271 (29.5\%) cases we used combination dexamethasone gel and depot form of corticosteroid intralesional. Differences in administered treatments are shown in Table 2.

\subsection{Malignant Transformation}

The median follow-up of all patients was 15.2 months (IQR 2.2-48.0 months). Overall, 2 patients $(2 / 271,0.74 \%)$ meeting above-mentioned criteria for malignant transformation were identified during the follow-up period. Both patients suffered from erosive OLP lesions and developed squamous cell carcinoma of the tongue. One patient was 74 years old male, and one was 60 years old female. The female patient was a smoker and the male patient had past history of transient smoking more than 30 years before the diagnosis. Details about both cases with oral squamous cell carcinoma (OSCC) are mentioned in Table 3.

Table 3. Description of the cases with malignant transformation.

\begin{tabular}{|c|c|c|}
\hline & Case \#1 & Case \#2 \\
\hline Gender & Female & Male \\
\hline Age at diagnosis of OLP (years) & 56.5 & 64.6 \\
\hline Age at diagnosis of malignancy (years) & 58.9 & 73.1 \\
\hline Smoking & yes, 10 pack years & stopped $30+$ years ago \\
\hline OLP type & reticular, erosive, erythematous & reticular, erosive \\
\hline Affected sites & tongue, buccal mucosa & tongue, buccal mucosa \\
\hline OLP high-risk HPV status & negative & negative \\
\hline Time to malignancy (months) & 28.8 & 102.1 \\
\hline Type of malignancy & OSCC & OSCC \\
\hline Initial malignancy site & tongue & tongue \\
\hline Extent of initial disease & T3N1M0 & T3N0M0 \\
\hline Treatment & $\begin{array}{l}\text { hemiglossectomy, lymph node resection, } \\
\text { adjuvant chemotherapy (cisplatin), } \\
\text { adjuvant radiotherapy (66 Gy IMRT } \\
\text { tongue + 59.4 Gy lymph nodes) }\end{array}$ & $\begin{array}{l}\text { hemiglossectomy, lymph node } \\
\text { resection, brachytherapy }\end{array}$ \\
\hline $\begin{array}{l}\text { Follow-up after OSCC } \\
\text { diagnosis (months) }\end{array}$ & 5.1 & 10.2 \\
\hline Outcome & death due to progression & alive \\
\hline
\end{tabular}

OSCC: oral squamous cell carcinoma, IMRT: intensity-modulated radiation therapy, Gy: gray, HPV human papilloma virus.

\section{Discussion}

The malignant potential of OLP has been a matter of ongoing long-term debate. Although there is a general agreement that the risk of malignant transformation is not high, the patients with OLP should be followed indefinitely. In a recent meta-analysis of 57 studies by Aghbari et al. an interesting observation was shown. The authors found that during the time period the overall proportion of patients transforming into cancer dropped from $5.9 \%$ in 1924 to currently reported $0.9 \%$ (CI $0.5-1.3$ ) [13]. This effect is probably given by the lack of diagnostic criteria of OLP before the year 2003 when van der Meij et al. modified the widely accepted WHO criteria for diagnosis of OLP [8]. The strict inclusion criteria are of paramount importance. The analysis by Idrees et al. stressed the risk of 
exaggeration of malignant transformation rate when diagnostic criteria are not strictly met [14]. In fact, OLP lesions tend to undergo malignant transformation less frequently than other oral potentially malignant disorders [15]. Our data showed a $0.74 \%$ transformation rate which seems to be in good agreement with the expected transformation rate.

One of the critically important issues is to distinguish between patients suffering from OLP and oral lichenoid lesions (OLL). OLL are those, not meeting the strict WHO criteria for OLP (examples include contact lesions, chronic graft versus host disease or druginduced lesions). Patients with OLL have generally higher malignant potential than those with OLP. González-Moles et al. in a recent meta-analysis reported $1.88 \%$ transformation rate for OLL and $1.14 \%$ for OLP [16]. On the other hand, some authors even question the clinical importance of distinguishing drug-induced lesions from OLP [17]. This same study by González-Moles et al. also included analysis of patients reported to have oral epithelial dysplasia (oral lichenoid dysplasia, OLD) which may be one of the key factors affecting the transformation rate. In a report by Sheraston et al., presence of OLD at the background of OLP resulted in higher malignant transformation than its absence. The authors reported a $0.49 \%$ rate in OLP patients without OLD and $6.81 \%$ in patients with OLD present. The average time to malignancy was rather short, 4.6 years [18]. On the other hand, the development of OLD during the course of the OLP seems to be a rather rare event. Guan et al. reported only $0.6 \%$ of patients who developed OLD during the course of the OLP disease [19].

Other risk factors of transformation include erosive type, female gender, and tongue localization. According to a systematic review published by Guiliani et al., 42.4\% (39/92) of OSCC cases were localized on the lateral side of the tongue with the majority having erosive lesions present [20]. Both of our patients presented with erosive lesions and had tongue involvement. It remains unknown whether infection with human papillomavirus (HPV) represents a risk factor for malignant transformation remains unknown. Recent meta-analysis showed association of OLP with HPV but so far no implication for cancer development [21]. No association of HPV and dysplastic changes in OLP was identified [22]. Our previous study found a significant proportion of OLP being positive for HPV as well as in healthy controls [23]. A Spanish study by Gomez-Armayones et al. found no association of HPV with OLP [24]. Both of our patients were OLP HPV negative.

An interesting study providing a high level of evidence was published by RamosGarcía et al. A systematic review of previously published systematic reviews was conducted. The authors included 7 previously published systematic reviews into the pooled analysis. The results confirmed the transformation rate in OLP to be $0.44-2.28 \%$, in OLL $1.88-3.8 \%$ and in OLP with dysplastic changes $6.22 \%$ highlighting the role of dysplasia presence [25].

Ruokonen et al. reported an interesting analysis of patients with OSCC with OLP, OLL or without any oral premalignant lesion. Another interesting note regarding this study was the fact, that majority of patients with OLP were diagnosed at early cancer stage (73\%). This fact underlines the necessity of careful long-term follow-up [26]. The authors also observed much less alcohol and tobacco consumption in patients with previous diagnosis of OLP or OLL which stresses the etiological role of OLP and OLL in cancer development. Another study conducted by Aguirre-Urizar et al. with 384 OLP and OLL patients and 10 cases of OSCC found $80 \%$ of patients affected by OSCC were non-smokers [27].

Insufficient data exist about the difference between survival rates of patients with OSCC arising from OLP. Muñoz et al. reported better, although not statistically significant survival of patients with OLP-related OSCC (119 vs. 42 months, $p=0.201)$ [28]. Bonnardot et al. reported shorter survival for OLP related OSCC (HR 1.43 CI 0.65-3.13) [29]. Analysis of Gonzáles-Moles et al. points to the fact that only these two trials reported the survival of patients with conflicting results. The meta-analysis did not show any meaningful difference in survival of patients with OLP-derived OSCC and OSCC without OLP (HR 1.00, CI 0.52-1.92) [30]. 
According to a consensus report published by Warnakulasuriya et al. on behalf of WHO Collaborative Center for Oral Cancer, OLP, OLL as well as oral chronic graft versus host disease represent oral potentially malignant disorders that are clearly associated with the risk of malignant transformation and should be followed accordingly [31].

\section{Conclusions}

We conclude that the malignant transformation rate of OLP in middle European population is not high $(0.74 \%)$. Nevertheless, OLP patients should be closely monitored for potential development of OSCC to ensure early diagnosis.

Author Contributions: V.R. designed the study, extracted data, wrote manuscript, R.K.I. conceptualized the work, reviewed and approved the manuscript, O.H. extracted data, R.S. conceptualized the work, reviewed and approved the manuscript. All authors have read and agreed to the published version of the manuscript.

Funding: The study was supported by the project PROGRES Q40/13 (Charles University, Faculty of Medicine in Hradec Králové) and by the Czech Health Research Council, Ministry of Health of the Czech Republic, MH CZ-DRO (UHHK, 00179906).

Institutional Review Board Statement: The study was approved by the Institutional Ethics Committee of University Hospital Hradec Králové, number 202006 S25P.

Informed Consent Statement: Patient consent was waived due to retrospective nature of the study.

Data Availability Statement: The data presented in this study are available on request from the corresponding author.

Conflicts of Interest: The authors declare no conflict of interest.

\section{References}

1. Alrashdan, M.S.; Cirillo, N.; McCullough, M. Oral lichen planus: A literature review and update. Arch. Dermatol. Res. 2016, 308, 539-551. [CrossRef]

2. DeAngelis, L.M.; Cirillo, N.; McCullough, M.J. The immunopathogenesis of oral lichen planus-Is there a role for mucosal associated invariant T cells? J. Oral Pathol. Med. 2019, 48, 552-559. [CrossRef]

3. Sugerman, P.B.; Savage, N.W.; Walsh, L.J.; Zhao, Z.Z.; Zhou, X.J.; Khan, A.; Seymour, G.J.; Bigby, M. The pathogenesis of oral lichen planus. Crit. Rev. Oral Biol. Med. 2002, 13, 350-365. [CrossRef]

4. González-Moles, M.Á.; Warnakulasuriya, S.; González-Ruiz, I.; González-Ruiz, L.; Ayén, Á.; Lenouvel, D.; Ruiz-Ávila, I.; Ramos-García, P. Worldwide prevalence of oral lichen planus: A systematic review and meta-analysis. Oral Dis. 2020. [CrossRef]

5. Andreasen, J.O. Oral lichen planus. 1. A clinical evaluation of 115 cases. Oral Surg. Oral Med. Oral Pathol. 1968, 25, 31-42. [CrossRef]

6. Scully, C.; Carrozzo, M. Oral mucosal disease: Lichen planus. Br. J. Oral Maxillofac. Surg. 2008, 46, 15-21. [CrossRef] [PubMed]

7. Gonzalez-Moles, M.A.; Scully, C.; Gil-Montoya, J.A. Oral lichen planus: Controversies surrounding malignant transformation. Oral Dis. 2008, 14, 229-243. [CrossRef]

8. van der Meij, E.H.; van der Waal, I. Lack of clinicopathologic correlation in the diagnosis of oral lichen planus based on the presently available diagnostic criteria and suggestions for modifications. J. Oral Pathol. Med. 2003, 32, 507-512. [CrossRef]

9. Al-Hashimi, I.; Schifter, M.; Lockhart, P.B.; Wray, D.; Brennan, M.; Migliorati, C.A.; Axéll, T.; Bruce, A.J.; Carpenter, W.; Eisenberg, E.; et al. Oral lichen planus and oral lichenoid lesions: Diagnostic and therapeutic considerations. Oral Surg. Oral Med. Oral Pathol. Oral Radiol. Endodontol. 2007, 103, S25.e1-S25.e12. [CrossRef]

10. Dudhia, B.B.; Dudhia, S.B.; Patel, P.S.; Jani, Y.V. Oral lichen planus to oral lichenoid lesions: Evolution or revolution. J. Oral Maxillofac. Pathol. 2015, 19, 364-370. [CrossRef] [PubMed]

11. Warnakulasuriya, S.; Johnson, N.W.; van der Waal, I. Nomenclature and classification of potentially malignant disorders of the oral mucosa. J. Oral Pathol. Med. 2007, 36, 575-580. [CrossRef]

12. González-Moles, M.Á.; Ramos-García, P.; Warnakulasuriya, S. An appraisal of highest quality studies reporting malignant transformation of oral lichen planus based on a systematic review. Oral Dis. 2020. [CrossRef]

13. Aghbari, S.M.H.; Abushouk, A.I.; Attia, A.; Elmaraezy, A.; Menshawy, A.; Ahmed, M.S.; Elsaadany, B.A.; Ahmed, E.M. Malignant transformation of oral lichen planus and oral lichenoid lesions: A meta-analysis of 20095 patient data. Oral Oncol. 2017, 68, 92-102. [CrossRef] [PubMed]

14. Idrees, M.; Kujan, O.; Shearston, K.; Farah, C.S. Oral lichen planus has a very low malignant transformation rate: A systematic review and meta-analysis using strict diagnostic and inclusion criteria. J. Oral Pathol. Med. 2020, 50, 287-298. [CrossRef] 
15. Iocca, O.; Sollecito, T.P.; Alawi, F.; Weinstein, G.S.; Newman, J.G.; De Virgilio, A.; Di Maio, P.; Spriano, G.; Pardiñas López, S.; Shanti, R.M. Potentially malignant disorders of the oral cavity and oral dysplasia: A systematic review and meta-analysis of malignant transformation rate by subtype. Head Neck 2020, 42, 539-555. [CrossRef]

16. González-Moles, M.Á.; Ruiz-Ávila, I.; González-Ruiz, L.; Ayén, Á.; Gil-Montoya, J.A.; Ramos-García, P. Malignant transformation risk of oral lichen planus: A systematic review and comprehensive meta-analysis. Oral Oncol. 2019, 96, 121-130. [CrossRef] [PubMed]

17. Fortuna, G.; Aria, M.; Schiavo, J.H. Drug-induced oral lichenoid reactions: A real clinical entity? A systematic review. Eur. J. Clin. Pharmacol. 2017, 73, 1523-1537. [CrossRef] [PubMed]

18. Shearston, K.; Fateh, B.; Tai, S.; Hove, D.; Farah, C.S. Oral lichenoid dysplasia and not oral lichen planus undergoes malignant transformation at high rates. J. Oral Pathol. Med. 2019, 48, 538-545. [CrossRef]

19. Guan, G.; Mei, L.; Polonowita, A.; Hussaini, H.; Seo, B.; Rich, A.M. Malignant transformation in oral lichen planus and lichenoid lesions: A 14-year longitudinal retrospective cohort study of 829 patients in New Zealand. Oral Surg. Oral Med. Oral Pathol. Oral Radiol. 2020, 130, 411-418. [CrossRef]

20. Giuliani, M.; Troiano, G.; Cordaro, M.; Corsalini, M.; Gioco, G.; Muzio, L.L.; Pignatelli, P.; Lajolo, C. Rate of malignant transformation of oral lichen planus: A systematic review. Oral Dis. 2019, 25, 693-709. [CrossRef] [PubMed]

21. Shang, Q.; Peng, J.; Zhou, Y.; Chen, Q.; Xu, H. Association of Human Papillomavirus With Oral Lichen Planus and Oral Leukoplakia: A Meta-analysis. J. Evid. Based Dent. Pract. 2020, 20, 101485. [CrossRef]

22. de la Cour, C.D.; Sperling, C.D.; Belmonte, F.; Syrjänen, S.; Kjaer, S.K. Human papillomavirus prevalence in oral potentially malignant disorders: Systematic review and meta-analysis. Oral Dis. 2021, 27, 431-438. [CrossRef]

23. Radochova, V.; Pliskova, L.; Slezak, R. HPV status in oral lichen planus in Eastern Bohemia. Oral Dis. 2014, $20,12$.

24. Gomez-Armayones, S.; Chimenos-Küstner, E.; Marí, A.; Tous, S.; Penin, R.; Clavero, O.; Quirós, B.; Pavon, M.A.; Taberna, M.; Alemany, L.; et al. Human papillomavirus in premalignant oral lesions: No evidence of association in a Spanish cohort. PLoS ONE 2019, 14, e0210070. [CrossRef] [PubMed]

25. Ramos-García, P.; González-Moles, M.Á.; Warnakulasuriya, S. Oral cancer development in lichen planus and related conditions-3.0 evidence level: A systematic review of systematic reviews. Oral Dis. 2021. [CrossRef]

26. Ruokonen, H.M.A.; Juurikivi, A.; Kauppila, T.; Heikkinen, A.M.; Seppänen-Kaijansinkko, R. High percentage of oral lichen planus and lichenoid lesion in oral squamous cell carcinomas. Acta Odontol. Scand. 2017, 75, 442-445. [CrossRef] [PubMed]

27. Aguirre-Urizar, J.-M.; Alberdi-Navarro, J.; Lafuente-Ibáñez de Mendoza, I.; Marichalar-Mendia, X.; Martínez-Revilla, B.; ParraPérez, C.; Juan-Galíndez, A.-D.; Echebarria-Goicouria, M.-Á. Clinicopathological and prognostic characterization of oral lichenoid disease and its main subtypes: A series of 384 cases. Med. Oral Patol. Oral Cir. Bucal 2020, 25, e554-e562. [CrossRef]

28. Muñoz, A.A.; Haddad, R.I.; Woo, S.-B.; Bhattacharyya, N. Behavior of oral squamous cell carcinoma in subjects with prior lichen planus. Otolaryngol. Head Neck Surg. 2007, 136, 401-404. [CrossRef]

29. Bonnardot, L.; Bardet, E.; Steichen, O.; Cassagnau, E.; Piot, B.; Salam, A.P.; Campion, L.; Ferron, C.; Beauvillain de Montreuil, C.; Malard, O. Prognostic factors for T1-T2 squamous cell carcinomas of the mobile tongue: A retrospective cohort study. Head Neck 2011, 33, 928-934. [CrossRef]

30. González-Moles, M.Á.; Warnakulasuriya, S.; González-Ruiz, I.; González-Ruiz, L.; Ayén, Á.; Lenouvel, D.; Ruiz-Ávila, I.; RamosGarcía, P. Clinicopathological and prognostic characteristics of oral squamous cell carcinomas arising in patients with oral lichen planus: A systematic review and a comprehensive meta-analysis. Oral Oncol. 2020, 106, 104688. [CrossRef]

31. Warnakulasuriya, S.; Kujan, O.; Aguirre-Urizar, J.M.; Bagan, J.V.; González-Moles, M.Á.; Kerr, A.R.; Lodi, G.; Mello, F.W.; Monteiro, L.; Ogden, G.R.; et al. Oral potentially malignant disorders: A consensus report from an international seminar on nomenclature and classification, convened by the WHO Collaborating Centre for Oral Cancer. Oral Dis. 2020. [CrossRef] [PubMed] 